\title{
An Experimental Study on the Configuration Management for the Construction of Tapered Concrete Pylon of Super Long Span Bridge Using K-Slip Form System
}

\author{
Won Jong Chin, Young Jin Kim, Hee Seok Kim, and Hyejin Yoon
}

\begin{abstract}
The Korea Institute of Construction Technology (KICT) developed the K-slip form system by improving radically the previous slip form system for the erection of the tapered concrete pylon of super long span bridge. This innovative K-slip form system adopts the latest tapered slip form design technology using BIM, lightweight GFRP module favoring the early strength development of concrete owing to its outstanding insulation, electromotive spindle for the sectional adjustment, estimation system of concrete strength using ultrasonic wave, remote control system of the hydraulic jacks for the raising of slip form, and GPS-based configuration management system. A $10 \mathrm{~m}$-high concrete pylon was erected successfully within 5 days using the K-slip form system as a mockup test. This paper focuses on the KICT Integrated Configuration Control System (KICS) developed for the configuration management of the tapered concrete pylon during its erection. The performance and applicability of KICS are validated through comparison of the measurement results provided simultaneously by the GPS-based KICS and the monitoring system traditionally adopted on site.
\end{abstract}

Index Terms-Slip form system, GPS, configuration management, tapered concrete pylon.

\section{INTRODUCTION}

The concrete pylon of super long span bridge must today satisfy not only economical but also aesthetical requirements. One can find $300 \mathrm{~m}$-high pylons with 3-dimensional tapered configuration varying along the height and inclined with respect to the vertical axis. However, the erection of the pylon's cross section varying with the height and, especially the 3-dimensional configuration of the pylon, relies nearly completely on the skill of foreign companies rather on Korean technology. The tapered pylons of Seohae Bridge completed in 2000 were the first ones to be erected by the slip form system. Even if the slip form system was applied to erect the concrete pylons of Yi Sun Sin Bridge, the largest suspension bridge in Korea in 2011 (main span length of 1,545 m), royalties reaching $20 \%$ of the pylon construction cost were disbursed to a foreign company for the use of the tapered slip form system. After completion of the pylons, the foreign company took all the drawings, equipment and parts away letting the Korean companies only with limited construction experience but without knowhow on the design, fabrication and operation of

Manuscript received April 9, 2014; revised July 3, 2014. This work was supported in part by the "Development of Accelerated Construction Technologies for High Pylons" project of the Super Long Span Bridge R\&D Program.

The authors are with the Korea Institute of Construction Technology, Republic of Korea (e-mail: wjchin@kict.re.kr, yjkim@kict.re.kr, lagoon@kict.re.kr, hiyoon@kict.re.kr). the tapered slip form system.

As part of the Super Long Span Bridge R\&D Program, the Korea Institute of Construction Technology (KICT) succeeded in overcoming the technical limits of the tapered slip form system after 4 years of research that started at the end of 2009. This enabled us to secure the design and construction technology of an innovative tapered slip form system providing safe and very fast construction and, adopting the latest lightweight GFRP form, estimation technique of the early setting of concrete, configuration management technology using GPS and IT, and remote and automated hydraulic control system. The development of the design and construction technology of the so-called K-slip form system can increase the portion of slip forming by $20 \%$ during the erection of the pylon of super long span bridge and reduce the construction cost of the pylon by more than $15 \%$.

Considering that the long span bridge market in Korea is expected to grow up to about 6.7 trillion KRW after 2011, the acquisition of such self-relying slip form technology represents a benefit of approximately 170 billion KRW. In view of its structural efficiency and economy, this system will find wide application for the erection of pylons higher than $400 \mathrm{~m}$ to be erected in cable stayed bridges with main span longer than $1,000 \mathrm{~m}$ and suspension bridges longer than 2,000 $\mathrm{m}$ [1].

This paper presents the development process of the K-slip form system and focuses particularly on the core technology constituted by the configuration management of tapered concrete pylon. Moreover, the applicability on field of the developed technology is verified through the mockup test of a 10 m-high concrete pylon [2].

\section{DEVElOPMENT OF K-SLIP FORM SySTEM}

Recently, concrete has become preferred to steel for the pylons of long span bridges owing to the development of the concrete construction technology and its economy. Mechanized and moving form system is applied to accelerate the erection of the concrete pylon and minimize elevated works [3]. Slip forming, also known to as sliding, stands for the repeated construction of a horizontal or vertical structure with a uniform shape and without construction joint. This technique places concrete continuously by lifting up the form system including the yoke leg and form-panel by means of a worm gear screw hydraulic jack attached to a rod embedded in the concrete mass of the pylon [4].

Until recently, the tapered slip forming of concrete pylons was impossible by the Korean technology and relied completely on the skill and equipment of foreign companies. 
Therefore, KICT developed the K-slip form system in a will to secure self-reliant technology for the super long span cable-supported bridge. This system constitutes a representative technological achievement surpassing any existing foreign slip form system in view of the following features. The first feature is the design technology of the tapered slip form equipment. The anticipated verification of the slip forming through a thorough analysis of the components of the tapered slip form system and the introduction of BIM (Building Information Modeling) opens ways for structural improvements and the optimal design by means of an advanced system. The development of such design technology of the slip form system constitutes an achievement securing an original design capacity.

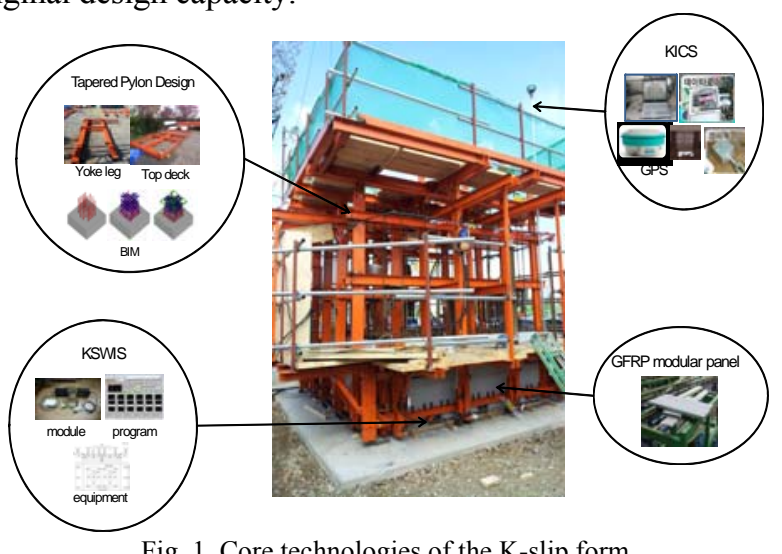

The second feature is the realization of lightweight slip form. The previous steel form is accompanied by serious delays in the assembling and dismantling process due to the need of manpower and equipment for the assemblage, dismantlement and transport of the components. Moreover, the dismantlement of the steel form at elevated height requires the mobilization of costly cranes due to the weight of the form. Therefore, modular lightweight GFRP (Glass Fiber Reinforced Plastic) panels were developed and applied for the first time in the world to reduce the weight of the form by half. The GFRP panel plays not only the role of form for placing concrete but also a structural role as tension stiffener for the whole system. This new panel offers multiple advantages like its resistance to salt attack in marine environment and the possibility to secure stable early quality of concrete owing to its insulating effect in winter [5].

The third feature is the automated lifting of the slip form. The ascension of the previous slip form system relied on experience by using a probing rod for estimating the strength developed by concrete. Such method not only delays the rise of the slip form but also leads to difficulty in securing consistent quality of concrete. Recalling that the strength development of concrete is a critical factor in the stable execution of the works for elevated tower structures, accidents can unfortunately occur [6]. The automated slip form lifting system (KSWIS) is an original and innovative technology controlling the slip form by estimating accurately the hardness at the surface of concrete in the form using ultrasonic wave. KSWIS is the very first technology measuring quantitatively and continuously the extent of setting of concrete so as to control automatically and safely the slip form from a remote control room [7].

The fourth feature is the development of KICS (KICT
Integrated Configuration control System), a configuration and construction precision management system minimizing errors for the precise erection of 3-dimensionally tapered high pylons. This system adopts GPS and remote controlled inclinometer to minimize the effect of climate and fit to the 3-dimensionally tapered section in the configuration management of the high pylon. The KICS enables to perform real-time monitoring of the verticality of tower structures higher than $400 \mathrm{~m}$ and presenting 3-dimensional shape like the pylon [8]. Fig. 1 illustrates the core technologies applied in the K-slip form system.

\section{DEVELOPMENT OF KICS (KiCt INTEGRATED CONFIGURATION CONTROL SYSTEM)}

The precise erection of the elevated concrete pylon necessitates a database collecting the observation of the environmental conditions around the bridge site and, the measurement of the corresponding structural responses. Therefore, a construction precision and configuration management system of the slip form was developed to minimize the effects of climate and 3-dimensionally tapered section. Here, a GPS and inclinometer were applied for all-weather measurement and research was implemented on data acquisition and processing methods for securing the precision. In order to achieve more effective construction precision management, solutions for the modular composition of the automated measurement system using GPS and inclinometer were derived. Accordingly, the hardware involving the PC control module, the GPS reception module, the data logger transmission module and the hydraulic jack controller and, the integrated software for the control of each device connected with the hardware were developed. This new type of integrated configuration control system (KICS) was finally established so as to monitor and control continuously the erection precision of the elevated pylon through closed loop control by collecting the data measured by the GPS and inclinometer attached to the slip form. The operation of KICS during slip forming proceeds by, first, determining the adequate rising height using the control $\mathrm{PC}$ that has received wirelessly the data from the GPS and inclinometer. Then, once the user transmits wirelessly his approval order for individual or the whole driving to the hydraulic pump, the hydraulic pump enters into action to lift up the hydraulic cylinder and control the rising and horizontality of the slip form. This routine is repeated until the target rising height. Fig. 2 shows the concept of the GPS-based KICS.

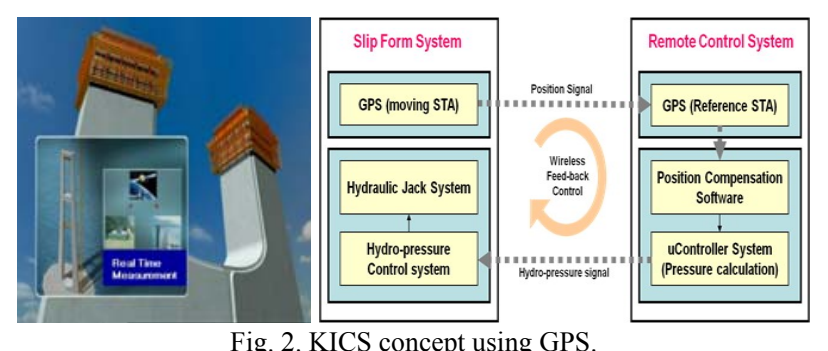

Fig. 3 illustrates the erection precision management algorithm of the slip form. Fig. 4 describes the concept of the wireless remote-controlled erection precision management and, Fig. 5 presents the main window of KICS. 
Since various validation tests are necessary to enhance the $t$ echnological completeness of KICS, numerous indoor and out door validation tests were performed preliminary during the $\mathrm{d}$ evelopment of the KICS software, and field test was also cond ucted [9]. This field test enabled to resolve the various proble ms of the system. Due to the absence of photograph depicting the erection of a pylon by the tapered slip form system, Fig. 6 presents a view of the KICS test conducted during the erectio $\mathrm{n}$ of the pylons of Ulsan Bridge by ACS.

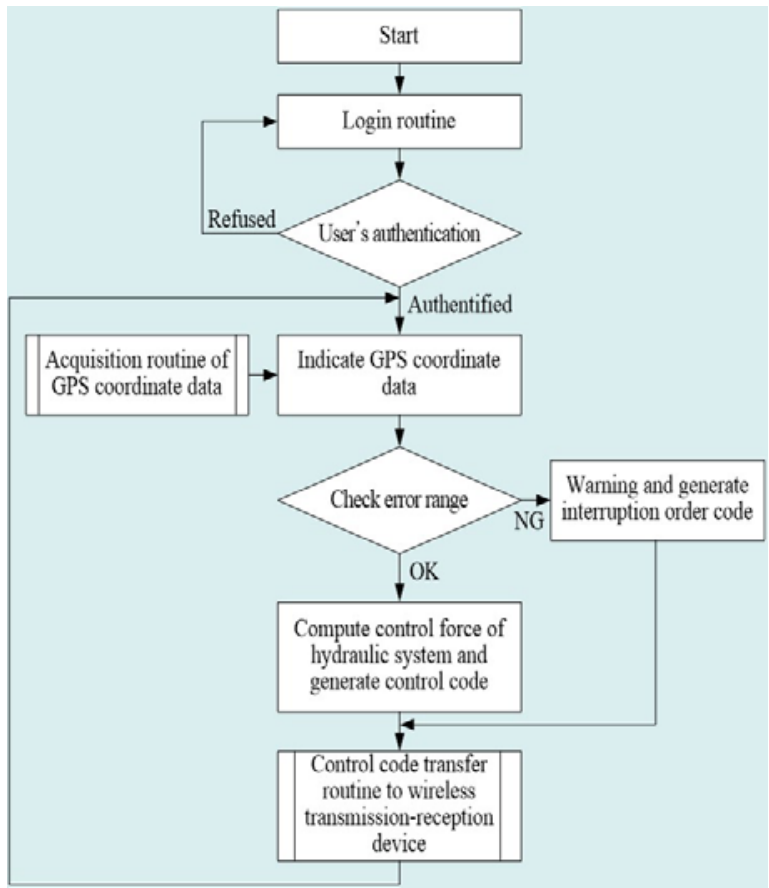

Fig. 3. Erection precision management algorithm of the slip form.

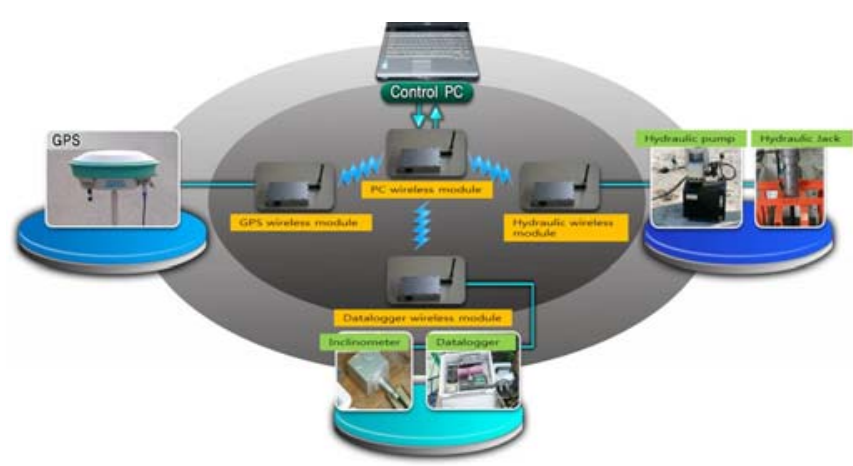

Fig. 4. Wireless-based remote erection precision management.

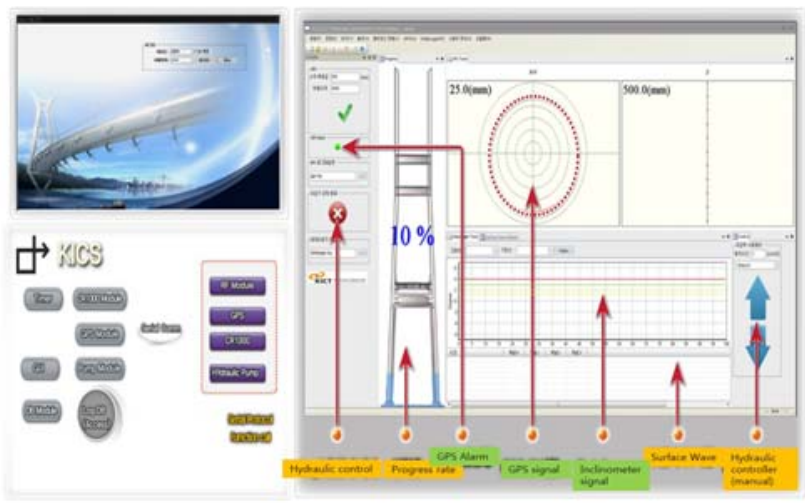

Fig. 5. Main window of KICS.

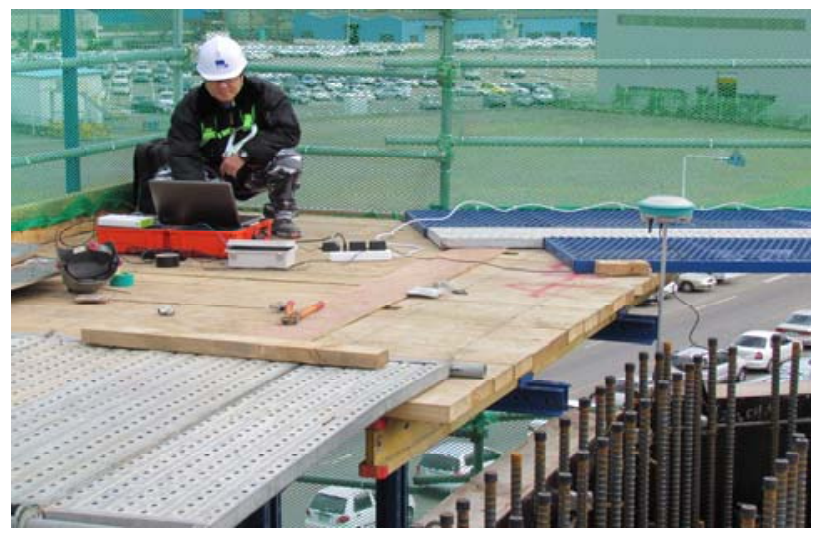

Fig. 6. Field applicability test (pylon erected by ACS).

\section{CONFIGURATION CONTROL DURING THE ERECTION OF A 10 M-High CONCRETE PYLON}

The performance of KICS was validated by comparing the measurement system used in previous concrete pylon construction site and the KICS during the simultaneous erection of a tapered concrete pylon with 2 legs and a latticed girder. The legs of the hollow concrete pylon adopted for the application of the K-slip form system present a height of $10 \mathrm{~m}$ and a tapered rectangular structure varying from $4 \mathrm{~m} \times 4 \mathrm{~m}$ at the base to $4 \mathrm{~m} \times 3.6 \mathrm{~m}$ at the top. The distance between the pylon legs is linked by a latticed girder erected to be inclined from $6 \mathrm{~m}$ at the base to $5.5 \mathrm{~m}$ at the top. Fig. 7 shows the dimensions of the two concrete legs applying the prototype of the K-slip form system. Fig. 8 illustrates the layout of the sensors and Fig. 9 shows a view of the slip forming of the concrete pylon [10].

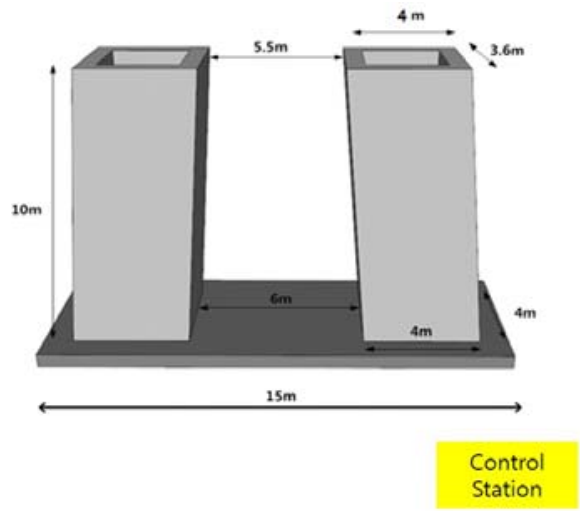

Fig. 7. Dimensions of the 2 concrete pylon legs.

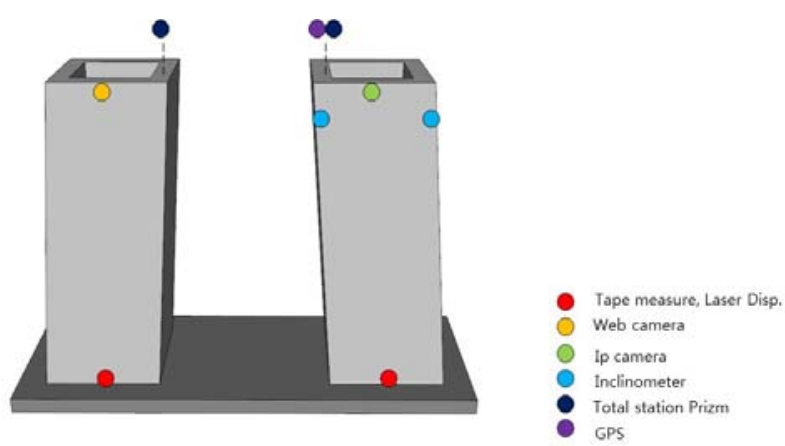

Control Station

Fig. 8. Layout of sensors. 


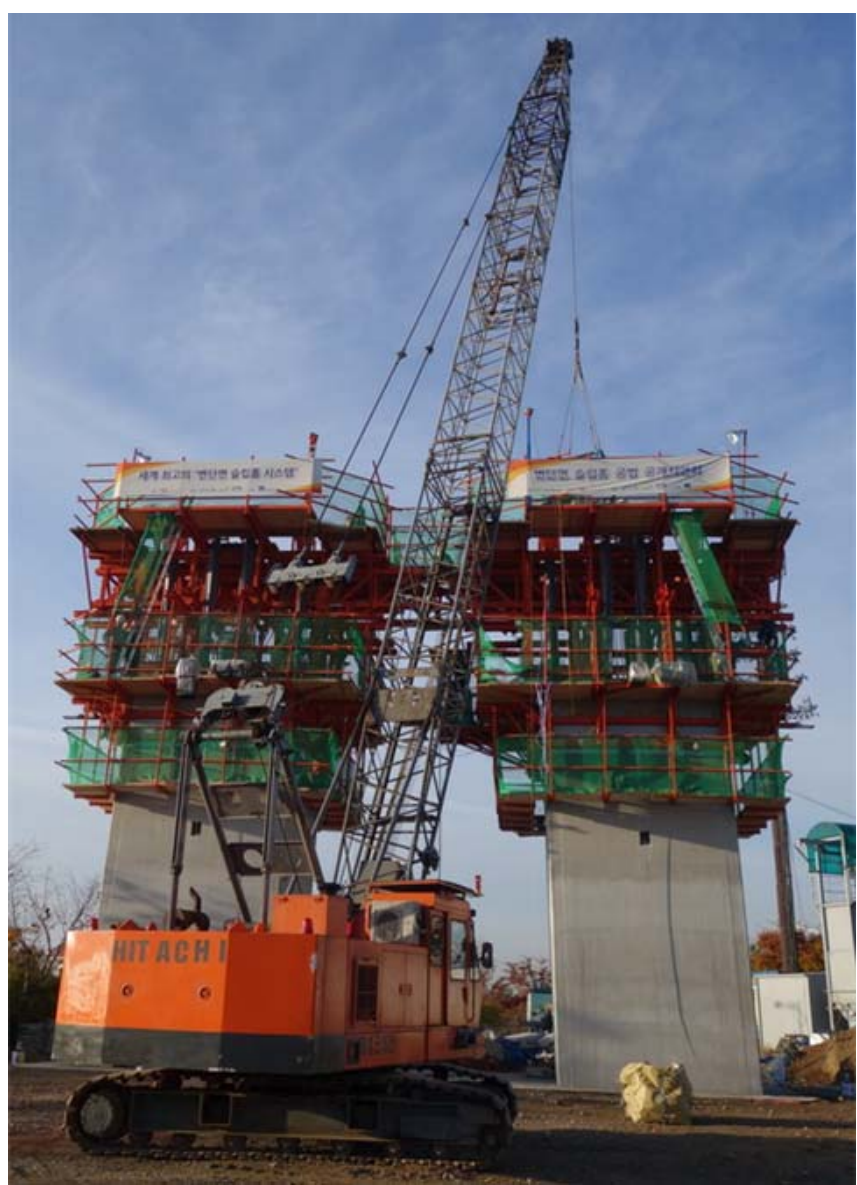

Fig. 9. Slip forming of concrete pylon.

The GPS method using a reference station and a moving station is used to improve the precision, and the data were collected using RTK (Real Time Kinematic) for real time data acquisition. Fig. 10 shows the installation of the GPS. The reference station was installed at a distance of approximately $60 \mathrm{~m}$ from the pylon construction site and the moving station was installed on the pylon leg 2. Fig. 11 shows the total station measurement. Fig. 12 compares the values of the height measured during slip forming by the GPS, tape ruler, laser distance meter and total station.

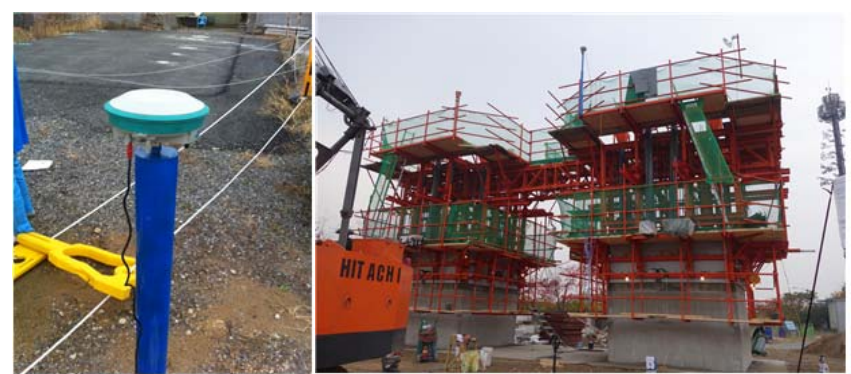

Fig. 10. Installation of the reference and moving station of the GPS.

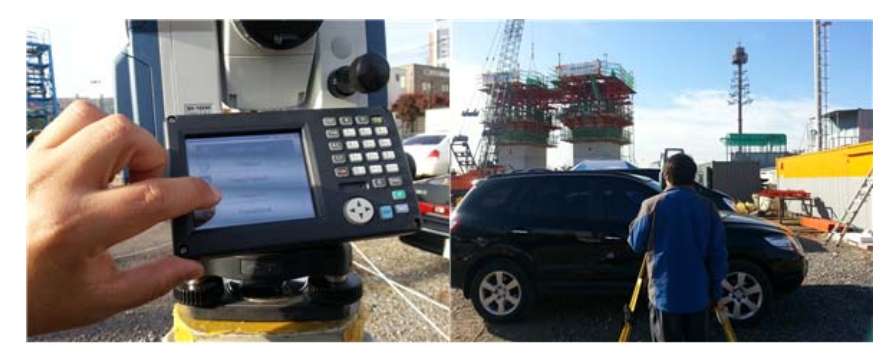

Fig. 11. Total station measurement.

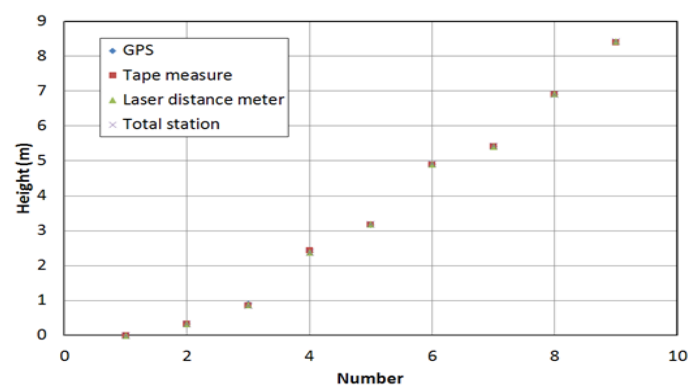

Fig. 12. Comparison of height measured by GPS, tape measure, laser distance meter and total station.

The horizontal displacements measured during slip forming were compared. Fig. 13 and Fig. 14 show respectively the plumb laser using IP camera and using web camera. These two types of plumb laser measurement were also developed in this study. Fig. 15 draws the final displacements of the cameras for the plumb laser measurement and GPS installed on the side of the slip form. Fig. 16 plots the displacement in the x-direction of leg 2 .
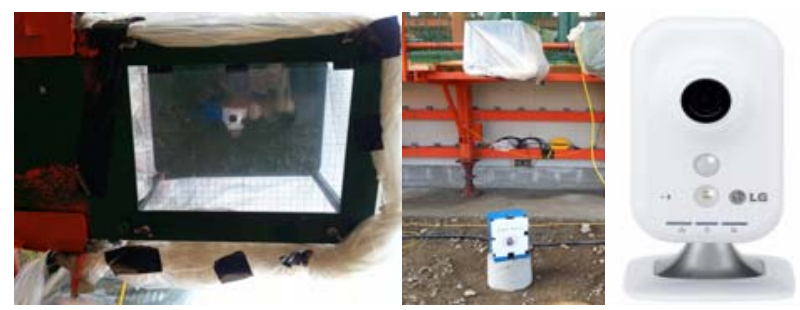

Fig. 13. Plumb laser using IP camera.

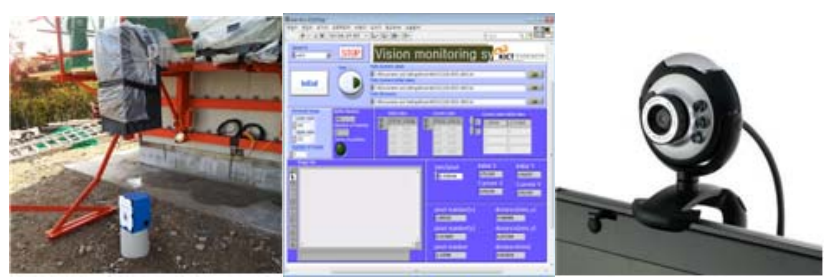

Fig. 14. Plumb laser using web camera.

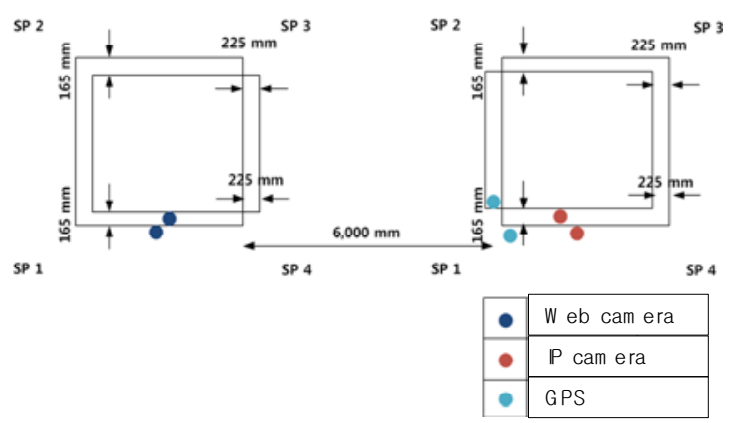

Fig. 15. Horizontal displacement of slip form.

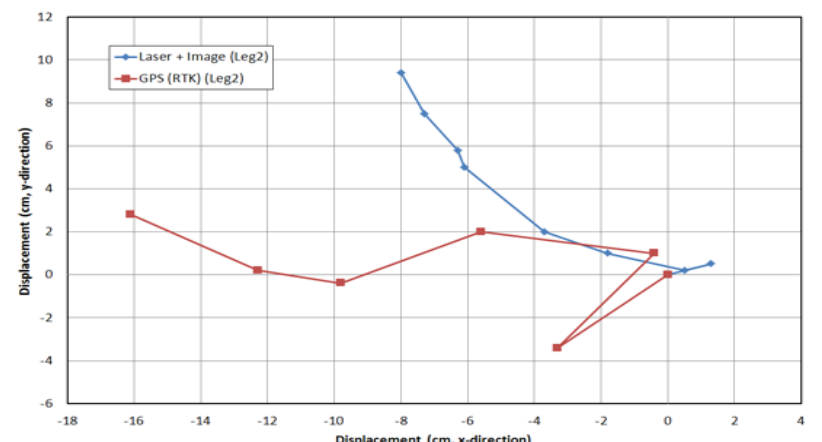

Fig. 16. x-axis displacement of leg 2. 
TABLE I: COMPARISON OF LATERAL DISPLACEMENT OF LEG 2

\begin{tabular}{llllll}
\hline \hline & & \multicolumn{2}{l}{ Theoretical value } & \multicolumn{2}{l}{ GPS value } \\
\cline { 3 - 6 } No. & Height $(\mathrm{m})$ & $\mathrm{x}(\mathrm{cm})$ & $\mathrm{y}(\mathrm{cm})$ & $\mathrm{x}(\mathrm{cm})$ & $\mathrm{y}(\mathrm{cm})$ \\
\hline 1 & 0.000 & 0.0 & 0.0 & 0.0 & 0.0 \\
2 & 0.326 & -0.8 & 0.5 & -3.3 & -3.4 \\
3 & 0.875 & -2.2 & 1.4 & -0.4 & 1.0 \\
4 & 2.421 & -6.1 & 4.0 & -5.6 & 2.0 \\
5 & 3.201 & -8.0 & 5.3 & -9.8 & -0.4 \\
6 & 4.913 & -12.3 & 8.1 & - & - \\
7 & 5.429 & -13.6 & 9.0 & -12.3 & 0.2 \\
8 & 6.918 & -17.3 & 11.4 & -16.1 & 2.8 \\
9 & 8.426 & -21.1 & 13.9 & - & - \\
\hline \hline
\end{tabular}

Since the plumb laser and the GPS are installed on the top of the slip form, the final theoretical variation of leg 1 at $10 \mathrm{~m}$ must be $22.5 \mathrm{~cm}$ in the $\mathrm{x}$-axis direction and $16.5 \mathrm{~cm}$ in the $y$-axis direction. For leg 2, the final theoretical variation at 10 $\mathrm{m}$ must be $22.5 \mathrm{~cm}$ in the $\mathrm{x}$-axis direction and $16.5 \mathrm{~cm}$ in the $y$-axis direction. At $8.426 \mathrm{~m}$, the final theoretical variation of leg 1 at $10 \mathrm{~m}$ must be $21.1 \mathrm{~cm}$ in the $\mathrm{x}$-axis direction and 13.9 $\mathrm{cm}$ in the $\mathrm{y}$-axis direction. For leg 2, the final theoretical variation at $8.426 \mathrm{~m}$ must be $21.1 \mathrm{~cm}$ in the $\mathrm{x}$-axis direction and $13.9 \mathrm{~cm}$ in the $y$-axis direction. However, for the lateral camera, the variations happened to be actually $15.8 \mathrm{~cm}$ in the $\mathrm{x}$-axis direction and $9.1 \mathrm{~cm}$ in the $\mathrm{y}$-axis direction for leg 1 and, $8.0 \mathrm{~cm}$ in the $\mathrm{x}$-axis direction and $9.4 \mathrm{~cm}$ in the $\mathrm{y}$-axis direction for leg 2.

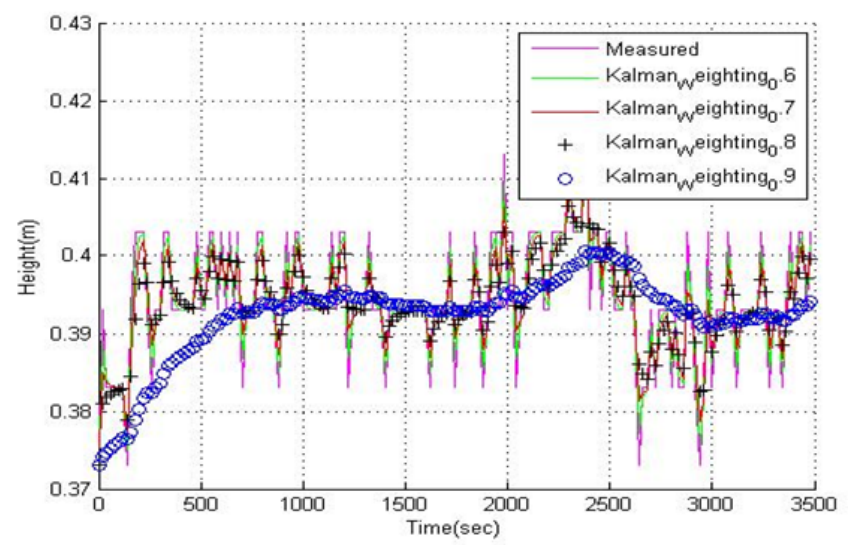

Fig. 17. Application of Kalman filter weighting

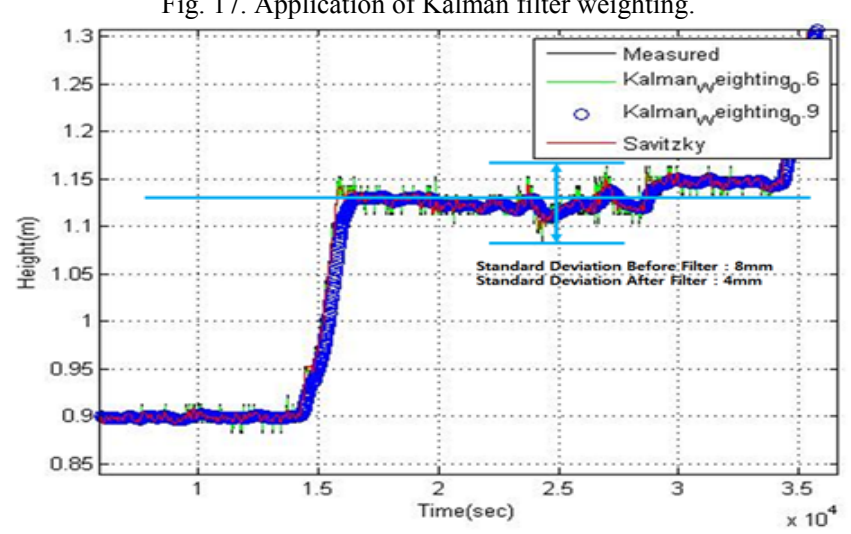

Fig. 18. Comparison of post-processed measurement data at rest of slip form

In view of the GPS results, the final variations at $6.918 \mathrm{~m}$ appeared to be $-16.1 \mathrm{~cm}$ in the $\mathrm{x}$-axis direction and $2.8 \mathrm{~cm}$ in the $y$-axis direction for leg 2(Table I). The significant difference with the theoretical value in the y-axis direction is due to the effect of the initial offset in the y-axis direction.
This initial offset seems to have been generated during the erection rather than during the data acquisition process. Further comparison with the reported events that occurred at the beginning of the erection process is necessary.

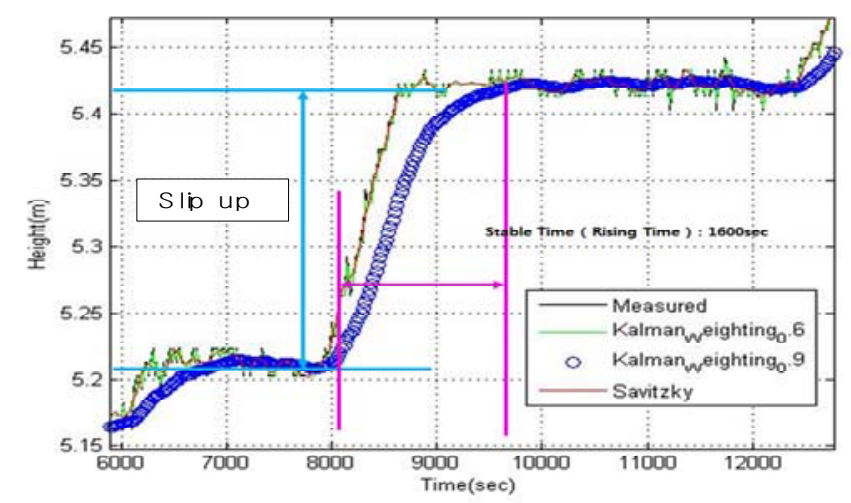

Fig. 19. Comparison of post-processed measurement data during slip up.
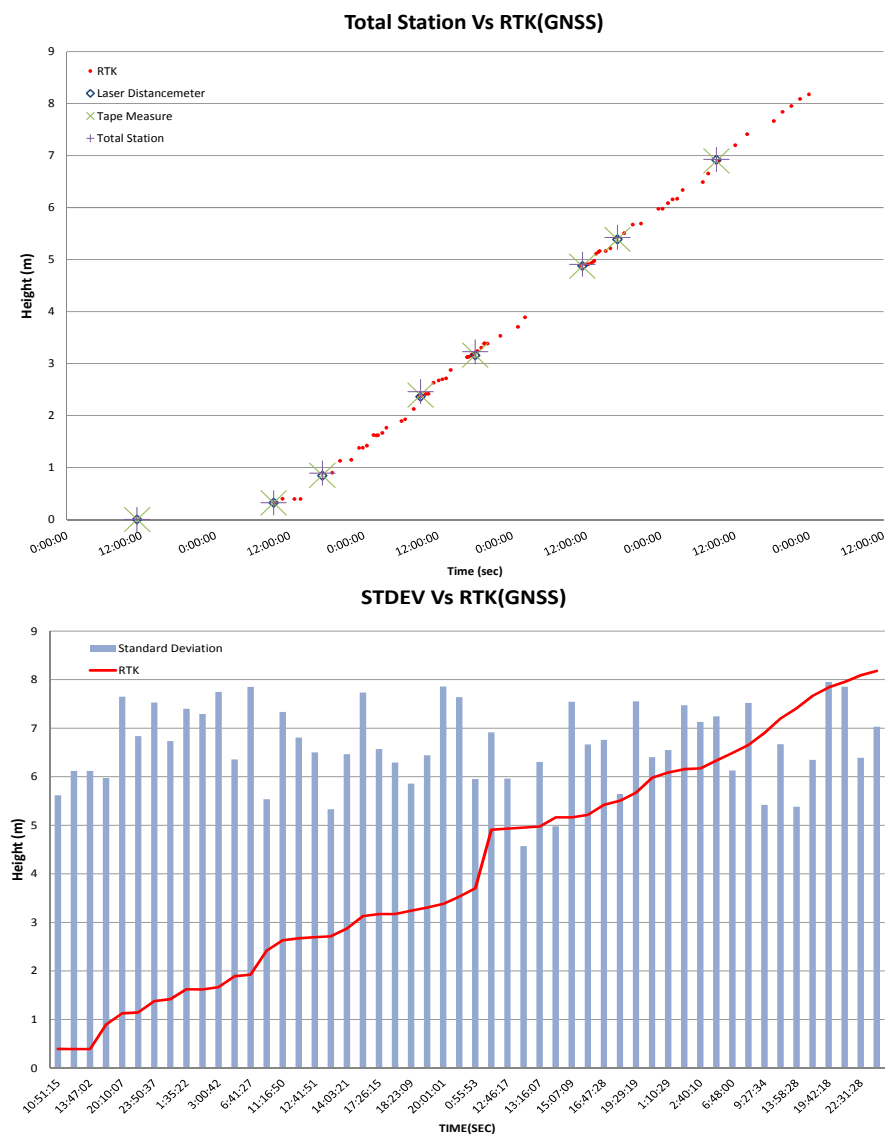

Fig. 20. Comparison of total station and tested RTK-GPS.

\section{Complementation of Signal Processing Module of GPS MEASUREMENT}

Currently, the KICS uses the RTK-GPS (Real time Kinematics GPS) value as real time positioning technique during the slip forming. In the case of slip forming which places concrete continuously 24 hours per day, the application of such real time positioning technique is appropriate. However, a signal post-processing technique can be suggested to secure higher accuracy of the GPS measurement signal.

In this study, the data acquired during the slip forming of 
the concrete pylon were processed by applying 4 types of Kalman filter weighting and the Savitzky-Golay filter [11]. Fig. 17 plots the graphs corresponding to the application of the Kalman filter weighting, and Fig. 18 plots the post-processed data at rest of the slip form. Fig. 19 plots the post-processed measurements at slip up.

As can be observed in Fig. 20, the trend shown by the RTK data within the range of measurement indicates that the measurement is controlled with a confidence level of $95 \%$ and a standard deviation of $\pm 10 \mathrm{~mm}$. It can be seen that the whole height is measured with very high accuracy. The analysis of the experimental data reveals that the data fall sufficiently within the control criteria since the Std. of the RTK data is smaller than $\pm 10 \mathrm{~mm}$ (Table II). In such case, the RTK can be expected to be of sufficient exploitability for the measurement equipment on field at the exception of the singular values caused by the wireless environment or other reasons. Moreover, even if the use of the Kalman filter can reduce the Std. down to $4 \mathrm{~mm}$, need is for a stabilization period after slip up of the form. In the test, accurate measurement can be done by applying the Kalman filter in the post-processing but, for the part applying the Kalman filter in real time, the erection process must be established preliminary for the measurement stabilization. Both Savitzky-Golay filter and Kalman Filter can be applied, and the Std. can be controlled via real time program. However, it is difficult to improve significantly the standard deviation by means of the Savitzky-Golay filter. Therefore, it is necessary to manage the data measurement by distinguishing the criteria during the erection through connection with the Kalman filter and the post-processed accurate measurement data.

TABLE II: DATA ANALYSIS RESULTS

\begin{tabular}{|c|c|c|c|}
\hline Data type & & Std (mm) & Characteristics \\
\hline Original data & & 10 & $\begin{array}{l}\text { Including RTK } \\
\text { divergent data }\end{array}$ \\
\hline Estimation data & & 10 & Real data \\
\hline \multirow{4}{*}{$\begin{array}{l}\text { Kalman } \\
\text { filter data }\end{array}$} & 0.6 & 9.3 & \multirow{3}{*}{$\begin{array}{l}\text { Stable time: quasi } \\
\text { similar }\end{array}$} \\
\hline & 0.7 & 8.7 & \\
\hline & 0.8 & 7.2 & \\
\hline & 0.9 & 4.1 & $\begin{array}{l}\text { Stable time: over } \\
1000 \mathrm{sec}\end{array}$ \\
\hline Savitzky-Golay filter data & & 8.3 & $\begin{array}{l}\text { Stable time: quasi } \\
\text { similar }\end{array}$ \\
\hline
\end{tabular}

\section{CONCLUSION}

This study developed the innovative K-slip form system for the slip forming of concrete pylons. The developed technology involves 4 core technologies of which the KICS (KICT Integrated Configuration control System). The application of the KICS enabled to conduct successfully the configuration management and slip up during the slip forming of the two legs of a $10 \mathrm{~m}$-high concrete pylon with tapered section using the K-slip form. This mockup test confirmed the field applicability of the developed technology. Further studies shall additionally deal with filtering methods in order to improve and complement the accuracy of the real time GPS measurement applied during slip forming, and complement the post-processing module of KICS. Moreover, additional studies shall also be implemented to improve the erection accuracy management technology by applying the KICS for the slip forming of the concrete pylons, piers and curbs of numerous super long span bridges.

\section{ACKNOWLEDGMENT}

This paper was supported by the "Development of Accelerated Construction Technologies for High Pylons" project of the Super Long Span Bridge R\&D Program. The authors express their gratitude for the support.

\section{REFERENCES}

[1] Development of construction equipment and method for the erection of high concrete pylon, KICT Report, 2012 (in Korean).

[2] J. W. Chun, Y. C. Lee, "Mock-up test of slip form method in seohae grand bridge," Daelim Technology \& Information, vol. 97, summer, pp. 99-107, 1997(in Korean).

[3] Standard Specifications for Temporary Constructions. Ministry of Construction and Transportation, 2006 (in Korean).

[4] K. T. Fossa, "Slipforming of Vertical Concrete Structures. Department of Structural Engineering," Ph.D. Thesis, Norwegian University of Science and Technology. N-7491 Trondheim Norway. 2001.

[5] Construction method of lightweight GFRP slip form, KICT Report, 2010 (in Korean).

[6] ACI 347-04, Guide to formwork for concrete, ACI 347, 2005.

[7] H. S. Kim et al., "A study on the determination of slip-up time for slip-form system using surface wave velocity," KSCE Journal of Civil Engineering, Korean Society of Civil Engineers, vol. 32, no. 5D, pp. 483-492, 2012 (in Korean).

[8] Y. J. Kim et al., "Development of tapered slip form system for the construction of the pylons of super long span bridges," Journal of Korea Construction Engineering Association, vol. 114, pp. 50-53, 2013 (in Korean).

[9] W. J. Chin et al., "Development of new verticality management and wireless control system for construction of main tower of cable stayed bridge," in Proc. 35th Conference of KSCE, pp. 2215-2218, 2009 (in Korean).

[10] W. J. Chin et al., "Innovative slip form method for the construction of tapered concrete pylon of long span cable bridge," in Proc. IABSE Symposium KOLKATA 2013, pp. 442 443, 2013

[11] Development of construction equipment and method for the erection of high concrete pylon, KICT Report, pp. 32 143, 2014 (in Korean).

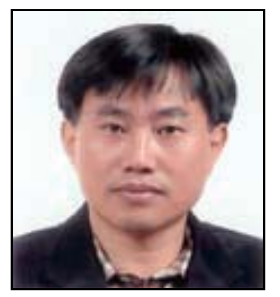

Y. J. Kim lives in Goyang, Korea. He received his $\mathrm{Ph} . \mathrm{D}$. in structural engineering in 2005 at the Department of Civil Engineering of Seoul National University. His major research topics deal with super long span bridge, UHPC bridge technology, and PS concrete structures. He is currently the director of the Global Technology Cooperation Center at the Korea Institute of Construction Technology, Goyang, Korea. Dr. Kim is a full member of the Korean Society of Civil Engineers and the Korea Concrete Institute.

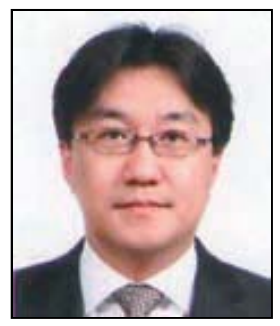

W. J. Chin lives in Seoul, Korea. He received his Master degree in structural engineering in 1999 at the Department of Civil Engineering of Myongji University. His major research topics deal with R\&D on erection equipment for high concrete pylons, dynamic characteristics of high-speed railway bridges and, R\&D on UHPC bridge technology. He is currently a principal research engineer at the Korea Institute of Construction Technology, Goyang, Korea. Mr. Chin is full member of the Korean Society of Civil Engineers and the Korea Concrete Institute. 


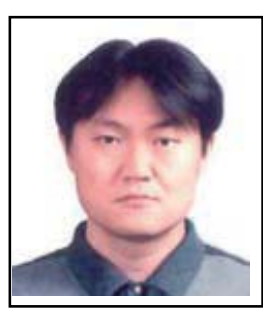

H. S. Kim lives in Seoul, Korea. He received his $\mathrm{Ph} . \mathrm{D}$. in structural engineering in 2008 at the Department of Civil Engineering of Hanyang University. His major research topics cope with the stress wave propagation and scattering analysis. $\mathrm{He}$ performed various projects involving dynamic analysis and finite element analysis, and $R \& D$ on erection equipment for high concrete pylons. He works currently as a post-doctoral researcher at the Korea Institute of Construction Technology, Goyang, Korea. Dr. Kim is full member of the Korean Society of Civil Engineers and the Korea Concrete Institute. He was awarded with the Best Paper Award of the Computational Structural Engineering Institute of Korea and the Young Scientist Award of the Korea Institute of Construction Technology.

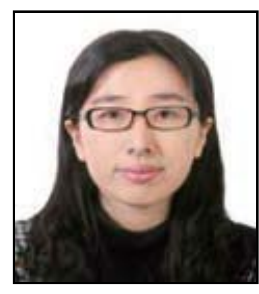

H. Yoon lives in Goyang, Korea. She completed the doctoral course in structural engineering in 2013 at the Department of Civil Engineering of Seoul National University. Her major research topics deal with R\&D on erection equipment for high concrete pylons, dynamic characteristics of high-speed railway bridges and, development of railway design load model. She is currently an associate research engineer at the Korea Institute of Construction Technology, Goyang, Korea. Ms. Yoon is a full member of the Korean Society of Civil Engineers and the Korea Concrete Institute. 